\title{
Neurogenesis in the aging brain
}

\author{
Veronica Galvan \\ Kunlin Jin
}

Buck Institute for Age Research, 800 I Redwood Blvd. Novato, CA, USA

Correspondence: Kunlin Jin

Buck Institute for Age Research,

800 I Redwood Blvd., Novato,

CA 94945-0638, USA

Tel + | 4I5 2092086

Fax + I 4I5 2092230

Email kjin@buckinstitute.org

\begin{abstract}
Neurogenesis, or the birth of new neural cells, was thought to occur only in the developing nervous system and a fixed neuronal population in the adult brain was believed to be necessary to maintain the functional stability of adult brain circuitry. However, recent studies have demonstrated that neurogenesis does indeed continue into and throughout adult life in discrete regions of the central nervous systems (CNS) of all mammals, including humans. Although neurogenesis may contribute to the ability of the adult brain to function normally and be induced in response to cerebral diseases for self-repair, this nevertheless declines with advancing age. Understanding the basic biology of neural stem cells and the molecular and cellular regulation mechanisms of neurogenesis in young and aged brain will allow us to modulate cell replacement processes in the adult brain for the maintenance of healthy brain tissues and for repair of disease states in the elderly.
\end{abstract}

Keywords: neurogenesis, aging, brain, neural stem cells, subgranular zone, subventricular zone

Until recently, a central assumption in neuroscience had been that new neurons do not arise in the adult mammalian brain. This idea prevailed in spite of reports, published in prominent journals, that showed that new neurons could arise in specialized areas of the brain (Altman 1963; Altman and Das 1965, 1966; Kaplan and Hinds 1977; Kaplan 1981). In the last few years, however, this belief has been challenged by numerous studies that demonstrated that certain areas of the brain retain pluripotent precursors with the capacity of self-renew and differentiation into new neural lineages in adult mammals such as rodents (Bayer 1983; Kuhn et al 1996; Kempermann et al 1997; Maslov et al 2004), non-human primates (Pencea, Bingaman, Freedman et al 2001), and humans (Eriksson et al 1998; Kukekov et al 1999; Magavi et al 2000). In rodents, it was shown that undifferentiated neural stem/progenitor cells (NSCs) are concentrated in the subventricular zone (SVZ) of the lateral ventricle wall (Maslov et al 2004) and the subgranular zone (SGZ) of the dentate gyrus of the hippocampus (Gage 2000). Cells born in the rodent SVZ during adult life travel anteriorly through the rostral migratory stream into the olfactory bulb (OB), where they differentiate into interneurons (Alvarez-Buylla 1997). Cells born in the SGZ of the dentate gyrus migrate a short distance to integrate in the granular layer (Gage 2000). The SGZ of the dentate gyrus in young adult rats contains about 9,400 dividing cells proliferating with a cell cycle time of 25 hours, which would generate 9,000 new cells each day, or more than 250,000 per month (Cameron and McKay 2001) and a high proportion of them differentiate into neurons (Hastings and Gould 1999; van Praag et al 2002). However, only about half of these newly generated neurons will survive after the first few weeks (Cameron et al 1993; Dayer et al 2003). Those that survive seem to integrate into preexisting hippocampal circuits and may permanently replace granule cells born during development (Dayer et al 2003). Remarkably, production overweighs loss of proliferating progenitors in the rat hippocampus such that neuronal cell numbers increase continuously until middle-age (Bayer et al 1982). 
That NSCs also exist in adult primate and human brain has now been well established (Kukekov et al 1999; Pencea, Bingaman, Freedman et al 2001; Bedard et al 2002; Bernier et al 2002; Bedard and Parent 2004) for the subependymal zone (Roy, Benraiss et al 2000), for the hippocampus (Eriksson et al 1998; Roy, Wang et al 2000) and very recently for the human olfactory bulb (Bedard and Parent 2004; Sanai et al 2004; Curtis et al 2007). The dentate gyrus and the hilus in cornus ammonis 4 (CA4) region of the human hippocampus are, however, the most active areas of NSC proliferation in adult non-human primates (Kornack and Rakic 1999) and humans (Eriksson et al 1998). NSCs are maintained in specialized microenvironments in these brain regions (Alvarez-Buylla and Lim 2004), in which they may undergo symmetrical division at a very low rate maintaining their pluripotency, or alternatively undergo asymmetric division to differentiate into neuronal precursors (NPs) (Ohnuma and Harris 2003; Sommer and Rao 2002).

Together with the refutation of the paradigm of 'brain constancy', a 'neurocentric' view of the brain is also being reconsidered. In addition to having an essential role in neural function, which can be thought of as mediated by neuronalglial systems as a whole (Lie et al 2004), the studies of AlvarezBuylla and coworkers (Lois et al 1996; Alvarez-Buylla et al 2001) and other groups (Anthony et al 2004) demonstrated that astrocytes in the SVZ and SGZ are NSCs in mammals and that radial glia may function as progenitors for the majority of neurons in mammalian central nervous system (CNS).

The neurogenicity of SVZ and SGZ NSCs in the young adult mammalian brain is restricted by signals from their local environment, as demonstrated with transplantation experiments that showed that SVZ cells loose their neurogenic potential if placed into non-spontaneously neurogenic regions of the brain (Alvarez-Buylla and Lim 2004). Conversely, after heterotopic transplantation into the hippocampus, NSCs isolated from the adult spinal cord can integrate in the granular cell layer and differentiate into cells characteristic of this region, whereas engraftment into other hippocampal regions resulted in the differentiation of cells with astroglial and oligodendroglial phenotypes. These observations suggested that multipotent adult progenitor cells from a non-neurogenic region are not lineage-restricted to their developmental origin but can generate region-specific neurons in vivo when exposed to the appropriate environmental cues (Shihabuddin et al 2000). Not surprisingly, developmental signal molecules and morphogens such as Notch (Artavanis-Tsakonas et al 1999; Givogri et al 2006), bone morphogenetic proteins, Noggin and sonic hedgehog (Pozniak and Pleasure 2006), have been implicated in the maintenance of adult neurogenic microenvironments (Lim et al 2000) containing glial and endothelial cells (Shen et al 2004).

The function of adult neurogenesis is still not known. In 2001, however, Shors et al (2001) showed that performance of a hippocampus-dependent learning task was dependent on the presence of replicating NSCs, suggesting that neurogenesis in the adult hippocampus has a role in learning memory (Shors et al 2001), although not all forms of hippocampal-dependent memory are associated with neurogenesis (Shors et al 2002; Meshi et al 2006). Deiseroth et al (2004) demonstrated that activity and neurogenesis are coupled, a process that would implement a form of network plasticity conceptually analogous to plasticity at the synaptic level, but occurring at the cellular network level. Indeed, organismal-level stimuli that entail an increase in neuronal activity such as learning (Gould, Beylin et al 1999; Leuner et al 2004), exposure to environmental enrichment (van Praag et al 1999; Brown et al 2003), exposure to hippocampaldependent learning tasks (Dayer et al 2003; Leuner et al 2004), and voluntary running (van Praag et al 1999; Brown et al 2003) have been shown to stimulate neurogenesis and enhance the survival of new neurons in the adult mammalian hippocampus, which in the case of running required vascular endothelial growth factor (VEGF) systemically (Fabel et al 2003; Cao et al 2004). Although neither of these behavioral interventions increased adult neurogenesis in the SVZ/OB (Brown et al 2003), proliferation in these areas was influenced by olfactory sensory enrichment. The observed increase in newborn neurons was concomitant with improved olfactory memory in enriched animals (Rochefort et al 2002). A pivotal role for adult neurogenesis in plasticity at the organismal level was indicated by recent studies showing that new granular cells formed in the epileptic rat dentate gyrus, but not in other conditions of neurogenesis stimulation, exhibited functional connectivity consistent with reduced excitability (Jakubs et al 2006). Taken together, these observations strongly suggest that activity of specific networks stimulates local neurogenesis and the survival of differentiated progenitors, which in turn contribute to enhanced function (Rochefort et al 2002), or act to mitigate dysfunction (Jakubs et al 2006).

Stem cells in neurogenic areas respond to other types of injury. Acute insults, such as focal ischemia induced by middle cerebral artery occlusion in rat, stimulate the proliferation of NSCs after extensive damage has occurred in the striatum and parietal cortex (Arvidsson et al 2002). Traumatic brain injury has also been reported to induce neurogenesis (Chirumamilla 
et al 2002), and this response can persist in the long term in the adult brain (Chen et al 2003). The activation of neurogenic processes as a response to chronic damage is much less well documented, although some (Curtis et al 2003; Jin, Galvan et al 2004; Jin, Peel et al 2004) but not all (Haughey, Liu et al 2002; Haughey, Nath et al 2002; Lazic et al 2004; Donovan et al 2006) studies have supported the hypothesis that slow neurodegenerative damage may also induce NSC proliferation. The evidence for de novo neurogenesis induced by chronic injury, however, is far from being definitive.

Although neurogenesis continues throughout life, its rate declines with increasing age in rodents (Seki and Arai 1995; Kuhn et al 1996; Kempermann et al 2002) and non-human primates (Gould, Reeves et al 1999). In aged rats, the proliferation rate of NSCs in the SGZ of the dentate gyrus is reduced by $80 \%$ (Jin et al 2003). The bulk of age-related decreases in SGZ neurogenesis takes place between 3 and 12 months of age (Kuhn et al 1996). In addition, the proportion of these NSCs that survive to become mature neuronal cells is reduced to half of that of young animals (Tang et al 2007). In contrast, the SVZ, the other prominently neurogenic area in rodent brain, suffers no significant (Kuhn et al 1996) or less severe (Jin et al 2003; Luo et al 2006) decreases in the rate of NSC proliferation.

The age-associated reduction in adult neurogenesis may be due to an intrinsic decline in NSC responsiveness to stimulating environmental cues, to a decrease in or disappearance of these environmental cues, or to the appearance or accumulation of inhibitory factors. Supporting a role for environmental cues in the age-associated decline in neurogenesis, it was shown that exogenous addition of growth factors such as insulin-like growth factor I (IGF-I) (Lichtenwalner et al 2001), epidermal growth factor (EGF) and fibroblast growth factor (FGF-2) (Jin et al 2003) or a reduction of corticosteroid levels by adrenalectomy (Cameron and McKay 1999) can, at least partially, negate the effects of age in the rate of NSC proliferation. Consistent with these observations, repeated social stress significantly decreased the rate of NSC proliferation in mice (Mitra et al 2006), while environmental enrichment (Kempermann et al 2002) and voluntary exercise (van Praag et al 1999) significantly reversed age-related decreases in NSC proliferation. Newly born neurons in aged mice were morphologically indistinguishable from those generated in young animals (van Praag et al 1999), and their increased numbers were accompanied by substantial and sustained behavioral improvements (Kempermann et al 2002). The observed increase in adult born neurons in older animals were at the expense of newly generated astrocytes, arguing that the effects of environmental enrichment affect the fate choice of proliferating multipotent progenitors or alternatively, specifically promote survival of newly born neurons. Environmental conditions may therefore have a crucial role in the modulation of neurogenesis during aging in rodents since like in young rodents experience, the stimulation of neurogenesis and improved functional outcomes may be causally linked in aged brains as well.

Age-associated memory deficits are broadly similar to those induced by damage to the hippocampus, which is one of several limbic structures implicated in the pathophysiology of mood disorders. It was recently shown that stress (Bremner et al 2003) and depression (Lloyd et al 2004; Stockmeier et al 2004; Frodl et al 2006) lead to hippocampal atrophy, while chronic antidepressant treatments result in an increase in hippocampal neurogenesis. Antidepressant action may require neurogenesis in mice (Santarelli et al 2003), although hippocampal neurogenesis was not required for the anxiolytic effects of environmental enrichment (Meshi et al 2006). It has been proposed that the age-related decline in neurogenesis may underlie age-associated learning and memory declines and may contribute to pathological conditions such as Alzheimer's disease (Haughey, Liu et al 2002; Haughey, Nath et al 2002; Donovan et al 2006). Although neurogenesis may contribute to function in the adult human CNS, the process does not suffice to preserve function during normal aging, or when injury or degenerative processes have ensued. However, that stimulation of NSC proliferation and possibly survival may be enhanced by growth factors or behavioral interventions even in older rodents (Benraiss et al 2001; Jin et al 2003; Pencea, Bingaman, Wiegand et al 2001) suggests that the endogenous neurogenic response could be modulated exogenously. Even though the overall level of endogenous neurogenesis is decreased in all mammals examined to date, the responsiveness of NSC proliferation is retained in aged mouse brains (Jin et al 2003) and human brains (Eriksson et al 1998). Remarkably, and albeit the sample number precluded drawing quantitative conclusions, Eriksson et al (1998) showed that the highest number of proliferating precursors in the granule cell layer and in the hilus of the dentate gyrus in human adults were found in subjects of middle and advanced age. How and to what extent our knowledge about neurogenic processes in rodents will ultimately translate to neurogenic processes in the adult primate brain is still unknown. In rodents, cells born in the SVZ travel anteriorly through the RMS into the OB, where they differentiate into interneurons (Alvarez-Buylla 1997). This process is referred 
to as "chain migration" (Lois and Alvarez-Buylla 1994). The RMS that continues to supply replacement interneurons to the rodent $\mathrm{OB}$ is weak in humans, possibly reflecting the reduced functionality of the human $\mathrm{OB}$. This is consistent with a reduced functionality of olfaction, as evidenced by the substantial loss of functional olfactory receptor genes in the human genome when compared to rodents. In 2004, however, a report by Bedard and Parent (2004) described cells expressing cell cycle markers and markers for immature neurons in the human $\mathrm{OB}$, suggesting that precursor proliferation may also occur, albeit at a much reduced rate, in this region of the adult human brain. The human RMS was finally demonstrated around a lateral ventricular extension reaching the $\mathrm{OB}$, the ventriculo-olfactory neurogenic system (VONS) which, in contrast to the rodent brain, takes a caudal path en route from the SVZ to the olfactory cortex as a consequence of the pronounced enlargement of the frontal cortex in the human forebrain that places the rostral caudate, SVZ and frontal cortex rostral to the olfactory tubercle (Curtis et al 2007). In contrast, the dentate gyrus and the hilus in CA4 region of the human hippocampus, which were detected earlier, are possibly the most active areas of progenitor proliferation in adult primates (Pencea, Bingaman, Freedman et al 2001) and humans (Eriksson et al 1998).

Apart from differences that likely reflect differential evolutionary paths in rodents and primates, available knowledge for neurogenesis in the two mammalian orders so far point to a fairly large degree conservation in the general regulation and in the impact of the aging in neurogenic processes.

Endogenous augmentation of trophic factor expression (such as brain-derived neurotrophic factor (BDNF), nerve growth factor (NGF), and FGF-2) in brains of laboratory animals has been achieved by behavioral interventions (Mattson 2004) such as enriched experience, voluntary exercise (Klintsova et al 2004) and training/learning (Will et al 2004). Both enriched housing and training have been shown to increase synaptogenesis (Carro et al 2002) and neurogenesis (van Praag et al 1999) as well. IGF-I has neuroprotective and neurogenic effects (Trejo, Carro, GarciaGalloway et al 2004; Trejo, Carro, Lopez-Lopez et al 2004) and it has been shown that peripheral infusion of IGF-I can increase NSC proliferation, selectively induce neurogenesis (Aberg et al 2000) and ameliorate the age-related decline in hippocampal neurogenesis in rats (Lichtenwalner et al 2001). The protective effects of physical exercise were shown to be mediated by circulating IGF-I (Carro et al 2001). A thorough consideration of the challenges to the design of treatment strategies based on the simulation of endogenous neurogenesis for replacement of affected networks, mainly centered on the delivery of growth factors, can be found in the review article by Lie et al (2004).

The ultimate requirement for neurogenesis to be beneficial in the adult is that it contributes to function, according to its cognitive and psychological definition (Kempermann et al 2004). Survival and acquisition of a neuronal phenotype by NSCs are dependent not only on network activity, but also on the existence of a complete environment capable of supporting survival, maturation and function by the production of neurotrophins and other regulators of proliferation and differentiation (Leavitt et al 1999; Oliet et al 2001; Smit et al 2001; Ullian et al 2001). When the network structures in which NSCs can integrate are compromised, as in normal aged brains or in neurodegerative conditions, increased proportions of proliferating progenitors may die. Would ongoing neurogenic processes positively contribute to enhanced function in all circumstances, or might there be a requirement for a minimal degree of integrity of network structures for neurogenesis to be beneficial? It is conceivable that the role of neurogenesis during the course of aging may be dictated by the degree of permissibility of the environment in which the process is taking place.

The discovery of neurogenesis and its role in the adult mammalian brain opened up exciting possibilities for the development of therapeutic interventions that might mitigate age-related learning and memory declines, and mood disorders. Even though the gaps in our understanding of the neurogenic process are not insignificant, it is likely that continuing investigation into the basic biology of adult NSCs will allow us to modulate cell replacement processes in the adult brain. As simple behavioral interventions can stimulate neurogenesis in rodent experimental models and possibly in humans, it is reasonable to suggest that lifestyle changes may constitute a therapeutic approach of low risk, albeit of variable efficacy, for the early prevention of age-associated or pathological cognitive decline. Behavioral interventions such as the diffusion of information required for lifestyle choices, the socialization of institutions providing access to continuing education, creative occupation, physical activity and the enjoyment of the arts may help societies increase their overall "cognitive reserve" and reduce the human, economic and social burden associated with increased numbers of cognitively impaired elderly in developed societies with high life expectancy.

\section{Acknowledgments}

This work was supported by grant NIRG-04-1054 from the Alzheimer's Association and a grant from the Bechtel 
Foundation to VG, and by National Institute of Health (NIH) grant AG21980 to KJ.

\section{References}

Aberg MAI, Aberg ND, Hedbacker H, et al. 2000. Peripheral infusion of IGF-I selectively induces neurogenesis in the adult rat hippocampus. J Neurosci, 20:2896-903.

Altman J. 1963. Autoradiographic investigation of cell proliferation in the brain of rats and cats. Postnatal growth and differentiation of the mammalian brain, with implications for a morphological theory of memory. Anat Rec, 145:573-91.

Altman J, Das GD. 1965. Autoradiographic and histological evidence of postnatal hippocampal neurogenesis in rat. J Comp Neurol, 124:319-36.

Altman J, Das GD. 1966. Autoradiographic and histological studies of postnatal neurogenesis. I. A longitudinal investigation of the kinetics, migration and transformation of cells incorporating tritiated thymidine in neonate rats, with special reference to postnatal neurogenesis in some brain regions. J Comp Neurol, 126:337-89.

Alvarez-Buylla A. 1997. Mechanism of migration of olfactory bulb interneurons. Semin Cell Dev Biol, 8:207-13.

Alvarez-Buylla A, Garcia-Verdugo JM, Tramontin AD. 2001. A unified hypothesis on the lineage of neural stem cells. Nat Rev Neurosci, 2:287-93.

Alvarez-Buylla A, Lim DA. 2004. For the long run: maintaining germinal niches in the adult brain. Neuron, 41:683-6.

Anthony TE, Klein C, Fishell G, et al. 2004. Radial glia serve as neuronal progenitors in all regions of the central nervous system. Neuron, 41:881-90.

Artavanis-Tsakonas S, Rand MD, Lake RJ. 1999. Notch signaling: cell fate control and signal integration in development. Science, 284:770-6.

Arvidsson A, Collin T, Kirik D, et al. 2002. Neuronal replacement from endogenous precursors in the adult brain after stroke. Nat Med, 8:963-70.

Bayer SA. 1983. 3H-thymidine-radiographic studies of neurogenesis in the rat olfactory bulb. Exp Brain Res, 50:329-40.

Bayer SA, Yackel JW, Puri PS. 1982. Neurons in the rat dentate gyrus granular layer substantially increase during juvenile and adult life. Science, 216:890-2.

Bedard A, Levesque M, Bernier PJ, et al. 2002. The rostral migratory stream in adult squirrel monkeys: contribution of new neurons to the olfactory tubercle and involvement of the antiapoptotic protein Bcl-2. Eur J Neurosci, 16:1917-24.

Bedard A, Parent A. 2004. Evidence of newly generated neurons in the human olfactory bulb. Brain Res Dev Brain Res, 151:159-68.

Benraiss A, Chmielnicki E, Lerner K, et al. 2001. Adenoviral brain-derived neurotrophic factor induces both neostriatal and olfactory neuronal recruitment from endogenous progenitor cells in the adult forebrain J Neurosci, 21:6718-31.

Bernier PJ, Bedard A, Vinet J, et al. 2002. Newly generated neurons in the amygdala and adjoining cortex of adult primates. PNAS, 99:11464-9.

Bremner JD, Vythilingam M, Vermetten E, et al. 2003. MRI and PET study of deficits in hippocampal structure and function in women with childhood sexual abuse and posttraumatic stress disorder. Am J Psychiatry, 160:924-32.

Brown J, Cooper-Kuhn CM, Kempermann G, et al. 2003. Enriched environment and physical activity stimulate hippocampal but not olfactory bulb neurogenesis. Eur J Neurosci, 17:2042-6.

Cameron HA, McKay RD. 1999. Restoring production of hippocampal neurons in old age. Nat Neurosci, 2:894-7.

Cameron HA, McKay RD. 2001. Adult neurogenesis produces a large pool of new granule cells in the dentate gyrus. J Comp Neurol, 435:406-17.

Cameron HA, Woolley CS, McEwen BS, et al. 1993. Differentiation of newly born neurons and glia in the dentate gyrus of the adult rat. Neuroscience, 56:337-44.
Cao L, Jiao X, Zuzga DS, et al. 2004. VEGF links hippocampal activity with neurogenesis, learning and memory. Nat Genet, 36:827-35.

Carro E, Trejo JL, Busiguina S, et al. 2001. Circulating insulin-like growth factor I mediates the protective effects of physical exercise against brain insults of different etiology and anatomy. $J$ Neurosci, 21:5678-84.

Carro E, Trejo JL, Gomez-Isla T, et al. 2002. Serum insulin-like growth factor I regulates brain amyloid-beta levels. Nat Med, 8:1390-7.

Chen XH, Iwata A, Nonaka M, et al. 2003. Neurogenesis and glial proliferation persist for at least one year in the subventricular zone following brain trauma in rats. $J$ Neurotrauma, 20:623-31.

Chirumamilla S, Sun D, Bullock MR, et al. 2002. Traumatic brain injury induced cell proliferation in the adult mammalian central nervous system. J Neurotrauma, 19:693-703.

Curtis MA, Kam M, Nannmark U, et al. 2007. Human neuroblasts migrate to the olfactory bulb via a lateral ventricular extension. Science, 315:1243-9.

Curtis MA, Penney EB, Pearson AG, et al. 2003. Increased cell proliferation and neurogenesis in the adult human Huntington's disease brain. PNAS, 100:9023-7.

Dayer AG, Ford AA, Cleaver KM, et al. 2003. Short-term and long-term survival of new neurons in the rat dentate gyrus. J Comp Neurol, 460:563-72.

Deisseroth K, Singla S, Toda H, et al. 2004. Excitation-neurogenesis coupling in adult neural stem/progenitor cells. Neuron, 42:535-52.

Donovan MH, Yazdani U, Norris RD, et al. 2006. Decreased adult hippocampal neurogenesis in the PDAPP mouse model of Alzheimer's disease. J Comp Neurol, 495:70-83.

Eriksson PS, Perfilieva E, Bjork-Eriksson T, et al. 1998. Neurogenesis in the adult human hippocampus. Nat Med, 4:1313-7.

Fabel K, Tam B, Kaufer D, et al. 2003. VEGF is necessary for exercise-induced adult hippocampal neurogenesis. Eur J Neurosci, 18:2803-12.

Frodl T, Schaub A, Banac S, et al. 2006. Reduced hippocampal volume correlates with executive dysfunctioning in major depression. J Psychiatry Neurosci, 31:316-23.

Gage FH. 2000. Mammalian neural stem cells. Science, 287:1433-8.

Givogri MI, de Planell M, Galbiati F, et al. 2006. Notch signaling in astrocytes and neuroblasts of the adult subventricular zone in health and after cortical injury. Dev Neurosci, 28:81-91.

Gould E, Beylin A, Tanapat P, et al. 1999. Learning enhances adult neurogenesis in the hippocampal formation. Nat Neurosci, 2:260-5.

Gould E, Reeves AJ, Fallah M, et al. 1999. Hippocampal neurogenesis in adult Old World primates. Proc Natl Acad Sci USA, 96:5263-7.

Hastings NB, Gould E. 1999. Rapid extension of axons into the CA3 region by adult-generated granule cells. J Comp Neurol, 413:146-54.

Haughey NJ, Liu D, Nath A, et al. 2002. Disruption of neurogenesis in the subventricular zone of adult mice, and in human cortical neuronal precursor cells in culture, by amyloid beta-peptide: implications for the pathogenesis of Alzheimer's disease. Neuromolecular Med, $1: 125-35$.

Haughey NJ, Nath A, Chan SL, et al. 2002. Disruption of neurogenesis by amyloid beta-peptide, and perturbed neural progenitor cell homeostasis, in models of Alzheimer's disease. J Neurochem, 83:1509-24.

Jakubs K, Nanobashvili A, Bonde S, et al. 2006. Environment matters: synaptic properties of neurons born in the epileptic adult brain develop to reduce excitability. Neuron, 52:1047-59.

Jin K, Galvan V, Xie L, et al. 2004. Enhanced neurogenesis in Alzheimer's disease transgenic (PDGF-APPSw, Ind) mice. PNAS, 101:13363-7.

Jin K, Peel AL, Mao XO, et al. 2004. Increased hippocampal neurogenesis in Alzheimer's disease. PNAS, 101:343-7.

Jin K, Sun Y, Xie L, et al. 2003. Neurogenesis and aging: FGF-2 and HB-EGF restore neurogenesis in hippocampus and subventricular zone of aged mice. Aging Cell, 2:175-83.

Kaplan MS. 1981. Neurogenesis in the 3-month-old rat visual cortex. J Comp Neurol, 195:323-38.

Kaplan MS, Hinds JW. 1977. Neurogenesis in the adult rat: electron microscopic analysis of light radioautographs. Science, 197:1092-4. 
Kempermann G, Gast D, Gage FH. 2002. Neuroplasticity in old age: Sustained fivefold induction of hippocampal neurogenesis by long-term environmental enrichment. Ann Neurol, 52:135-43.

Kempermann G, Kuhn HG, Gage FH. 1997. More hippocampal neurons in adult mice living in an enriched environment. Nature, 386:493-5.

Kempermann G, Wiskott L, Gage FH. 2004. Functional significance of adult neurogenesis. Curr Opin Neurobiol, 14:186-91.

Klintsova AY, Dickson E, Yoshida R, et al. 2004. Altered expression of BDNF and its high-affinity receptor TrkB in response to complex motor learning and moderate exercise. Brain Res, 1028:92-104.

Kornack DR, Rakic P. 1999. Continuation of neurogenesis in the hippocampus of the adult macaque monkey. PNAS, 96:5768-73.

Kuhn HG, Dickinson-Anson H, Gage FH. 1996. Neurogenesis in the dentate gyrus of the adult rat: age-related decrease of neuronal progenitor proliferation. J Neurosci, 16:2027-33.

Kukekov VG, Laywell ED, Suslov O, et al. 1999. Multipotent stem/progenitor cells with similar properties arise from two neurogenic regions of adult human brain. Exp Neurol, 156:333-44.

Lazic SE, Grote H, Armstrong RJ, et al. 2004. Decreased hippocampal cell proliferation in R6/1 Huntington's mice. Neuroreport, 15:811-13.

Leavitt BR, Hernit-Grant CS, Macklis JD. 1999. Mature astrocytes transform into transitional radial glia within adult mouse neocortex that supports directed migration of transplanted immature neurons. Exp Neurol, 157:43-57.

Leuner B, Mendolia-Loffredo S, Kozorovitskiy Y, et al. 2004. Learning enhances the survival of new neurons beyond the time when the hippocampus is required for memory. $J$ Neurosci, 24:7477-81.

Lichtenwalner RJ, Forbes ME, Bennett SA, et al. 2001. Intracerebroventricular infusion of insulin-like growth factor-I ameliorates the age-related decline in hippocampal neurogenesis. Neuroscience, 107:603-13.

Lie DC, Song H, Colamarino SA, et al. 2004. Neurogenesis in the adult brain: new strategies for central nervous system diseases. Annu Rev Pharmacol Toxicol, 44:399-421.

Lim DA, Tramontin AD, Trevejo JM, et al. 2000. Noggin antagonizes BMP signaling to create a niche for adult neurogenesis. Neuron, 28:713-26.

Lloyd AJ, Ferrier IN, Barber R, et al. 2004. Hippocampal volume change in depression: late- and early-onset illness compared. Br J Psychiatry, 184:488-95.

Lois C, Alvarez-Buylla A. 1994. Long-distance neuronal migration in the adult mammalian brain. Science, 264:1145-8.

Lois C, Garcia-Verdugo JM, Alvarez-Buylla A. 1996. Chain migration of neuronal precursors. Science, 271:978-81.

Luo J, Daniels SB, Lennington JB, et al. 2006. The aging neurogenic subventricular zone. Aging Cell, 5:139-52.

Magavi SS, Leavitt BR, Macklis JD. 2000. Induction of neurogenesis in the neocortex of adult mice. Nature, 405:951-5.

Maslov AY, Barone TA, Plunkett RJ, et al. 2004. Neural stem cell detection, characterization, and age-related changes in the subventricular zone of mice. J Neurosci, 24:1726-33.

Mattson MP. 2004. Pathways towards and away from Alzheimer's disease. Nature, 430:631-9.

Meshi D, Drew MR, Saxe M, et al. 2006. Hippocampal neurogenesis is not required for behavioral effects of environmental enrichment. Nat Neurosci, 9:729-31.

Mitra R, Sundlass K, Parker KJ, et al. 2006. Social stress-related behavior affects hippocampal cell proliferation in mice. Physiol Behav, 89:123-7.

Ohnuma S, Harris WA. 2003. Neurogenesis and the cell cycle. Neuron, 40:199-208.

Oliet SH, Piet R, Poulain DA. 2001. Control of glutamate clearance and synaptic efficacy by glial coverage of neurons. Science, 292:923-6.
Pencea V, Bingaman KD, Freedman LJ, et al. 2001. Neurogenesis in the subventricular zone and rostral migratory stream of the neonatal and adult primate forebrain. Exp Neurol, 172:1-16.

Pencea V, Bingaman KD, Wiegand SJ, et al. 2001. Infusion of brain-derived neurotrophic factor into the lateral ventricle of the adult rat leads to new neurons in the parenchyma of the striatum, septum, thalamus, and hypothalamus. $J$ Neurosci, 21:6706-17.

Pozniak CD, Pleasure SJ. 2006. A tale of two signals: Wnt and Hedgehog in dentate neurogenesis. Sci STKE, 2006:pe5.

Rochefort C, Gheusi G, Vincent J-D, et al. 2002. Enriched odor exposure increases the number of newborn neurons in the adult olfactory bulb and improves odor memory. J Neurosci, 22:2679-89.

Roy NS, Benraiss A, Wang S, et al. 2000. Promoter-targeted selection and isolation of neural progenitor cells from the adult human ventricular zone. J Neurosci Res, 59:321-31.

Roy NS, Wang S, Jiang L, et al. 2000. In vitro neurogenesis by progenitor cells isolated from the adult human hippocampus. Nat Med, 6:271-7.

Sanai N, Tramontin AD, Quinones-Hinojosa A, et al. 2004. Unique astrocyte ribbon in adult human brain contains neural stem cells but lacks chain migration. Nature, 427:740-4.

Santarelli L, Saxe M, Gross C, et al. 2003. Requirement of hippocampal neurogenesis for the behavioral effects of antidepressants. Science, 301:805-9.

Seki T, Arai Y. 1995. Age-related production of new granule cells in the adult dentate gyrus. Neuroreport, 6:2479-82.

Shen Q, Goderie SK, Jin L, et al. 2004. Endothelial cells stimulate selfrenewal and expand neurogenesis of neural stem cells. Science, 304:1338-40.

Shihabuddin LS, Horner PJ, Ray J, et al. 2000. Adult spinal cord stem cells generate neurons after transplantation in the adult dentate gyrus. J Neurosci, 20:8727-35.

Shors TJ, Miesegaes G, Beylin A, et al. 2001. Neurogenesis in the adult is involved in the formation of trace memories. Nature, 410:372-6.

Shors TJ, Townsend DA, Zhao M, et al. 2002. Neurogenesis may relate to some but not all types of hippocampal-dependent learning. Hippocampus, 12:578-84.

Smit AB, Syed NI, Schaap D, et al. 2001. A glia-derived acetylcholine-binding protein that modulates synaptic transmission. Nature, 411:261-8.

Sommer L, Rao M. 2002. Neural stem cells and regulation of cell number. Prog Neurobiol, 66:1-18.

Stockmeier CA, Mahajan GJ, Konick LC, et al. 2004. Cellular changes in the postmortem hippocampus in major depression. Biol Psychiatry, 56:640-50.

Tang H, Wang Y, Xie L, et al. 2007. Effect of neural precursor proliferation level on neurogenesis in rat brain during aging and after focal ischemia. Neurobiol Aging in press.

Trejo JL, Carro E, Garcia-Galloway E, et al. 2004. Role of insulin-like growth factor I signaling in neurodegenerative diseases. $J \mathrm{Mol} \mathrm{Med}$, 82:156-62.

Trejo JL, Carro E, Lopez-Lopez C, et al. 2004. Role of serum insulin-like growth factor I in mammalian brain aging. Growth Horm IGF Res, 14 (Suppl A):S39-43.

Ullian EM, Sapperstein SK, Christopherson KS, et al. 2001. Control of synapse number by glia. Science, 291:657-61.

van Praag H, Christie BR, Sejnowski TJ, et al. 1999. Running enhances neurogenesis, learning, and long-term potentiation in mice. Proc Natl Acad Sci USA, 96:13427-31.

van Praag H, Schinder AF, Christie BR, et al. 2002. Functional neurogenesis in the adult hippocampus. Nature, 415:1030-4.

Will B, Galani R, Kelche C, et al. 2004. Recovery from brain injury in animals: relative efficacy of environmental enrichment, physical exercise or formal training (1990-2002). Prog Neurobiol, 72:167-82. 